\title{
Diagnosis of mitochondrial encephalomyopathy, lactic acidosis, and stroke-like episodes in a Chinese family by PCR/restriction enzyme analysis
}

\author{
C W Lam, K Jain, K Y Chan, D K Silva, Y W Chan, L J C Wong
}

\begin{abstract}
The clinical presentation and the biochemical and molecular genetic findings are described in a 13 year old Chinese boy with MELAS (mitochondrial encephalomyopathy, lactic acidosis, and stroke-like episodes). The diagnosis was initially suspected because of the characteristic clinical features and the strong family history of convulsions. Using polymerase chain reaction-restriction enzyme analysis, the heteroplasmic nt3243 $A \rightarrow G$ mutation in mtDNA of peripheral blood leucocytes and a muscle sample was demonstrated. The oligosymptomatic relatives were then screened by this method and the degree of heteroplasmy was analysed. This appears to be the first report of a MELAS family in Hong Kong with this described mutation. Molecular genetic techniques are advantageous in the diagnosis of MELAS.
\end{abstract}

(f Clin Pathol: Mol Pathol 1995;48:M285-M288)

Keywords: Mitochondrial encephalomyopathy, MELAS syndrome, mitochondrial mutation.

Mitochondrial encephalomyopathy, lactic acidosis, and stroke-like episodes (MELAS) is one of the maternally inherited mitochondrial diseases and was first described by Pavlakis et al ${ }^{1}$ in 1984. For many years, the diagnosis was based mainly on clinical features. Subsequent studies showed that this disease was usually associated with respiratory chain enzyme defects, particularly of $\mathrm{NADH}$ dehydrogenase (complex I). In 1990, Goto et $a l^{2}$ identified a point mutation in mitochondrial DNA of a MELAS patient, with nt $3243 \mathrm{~A} \rightarrow \mathrm{G}$ mutation in the transfer $\mathrm{RNA}^{\mathrm{Leu}(\mathrm{UUR})}$ gene. This mutation was subsequently found in over $80 \%$ of MELAS patients and their oligosymptomatic relatives. ${ }^{3}$ In this report, we described a family segregating this mutation. Using molecular genetic techniques we have screened 10 family members and confirmed the diagnosis in those affected. To the best of our knowledge, this is the first MELAS family with this documented mutation in Hong Kong.

\section{Case report}

The patient (III1) was a 13 year old Chinese boy with a normal prenatal, perinatal, and developmental history. He was otherwise well until the age of 10 years, when he experienced intermittent headache and lethargy. At 12 years of age, he was admitted to hospital with repeated generalised clonic convulsions and phenobarbitone was started. Three months later he was readmitted for severe migraine over the left frontal region, vomiting, and focal convulsion followed by transient right hemiparesis and right homonymous hemianopia. $\mathrm{He}$ also had dysphasia and mental deterioration. An electroencephalogram (EEG) revealed diffuse slow waves with left mid-temporal and central epileptiform discharges. Bilateral basal ganglia calcification was evident on computerised tomography (CT). Magnetic resonance imaging (MRI) of the brain was performed after the first stroke-like episode and showed increased signal intensity in T2 weighted images in the left temporal and parieto-occipital areas. The deproteinated blood lactate concentration was $4.8 \mathrm{mmol} / 1$ (normal: $0.5-1.3 \mathrm{mmol} / \mathrm{l}$ ) and pyruvate was $188 \mu \mathrm{mol} / 1$ (normal: $45-80 \mu \mathrm{mol} / \mathrm{l}$ ), with a lactate/pyruvate ratio of $25 \cdot 5$ (normal: 6-14). The results of all other serum laboratory tests were normal. A biopsy obtained from the right quadriceps muscle showed "ragged red fibres" in the modified Gomori trichrome stain and high succinate dehydrogenase (SDH) and nicotinamide adenine dinucleotide-tetrazolium reductase (NADH-TR) activities. Electron microscopy revealed aggregates of giant mitochondria with abnormal cristae and intramatrical electrondense granules. The patient was treated with carbamazepine, phenytoin, thiamine, riboflavin, coenzyme $Q_{10}$, and prednisone with apparent beneficial effect.

The patient had a strong family history of similar illness. His mother (II1) had a long history of repeated convulsions and died at the age of 33 years from status epilepticus. Her CT brain scan at that time showed bilateral basal ganglia calcification. The maternal aunt (II5) also had a history of status epilepticus and encephalopathy at the age of 20 years. 
However, she recovered completely from that episode and suffered no further attacks. The cause for her illness was not determined. All the cousins of the patient (III3, III4, III5) suffered from neurological disorders. Patient III3 presented with status epilepticus and encephalopathy at the age of 8 years and recovered, though having occasional fits. The other two cousins, III4 and III5, were both diagnosed as having spinal muscular atrophy. Patient III4 is now wheelchair bound, and patient III5 died at the age of 3 years from bronchopneumonia and respiratory failure. The patient's elder brother (III2) is now 16 years old. Initially he did not have any apparent neurological abnormality apart from being easily fatigued. Although there was no past history of convulsions, his muscle biopsy showed ragged red fibres. However, 3 months after the muscle biopsy was taken, he developed
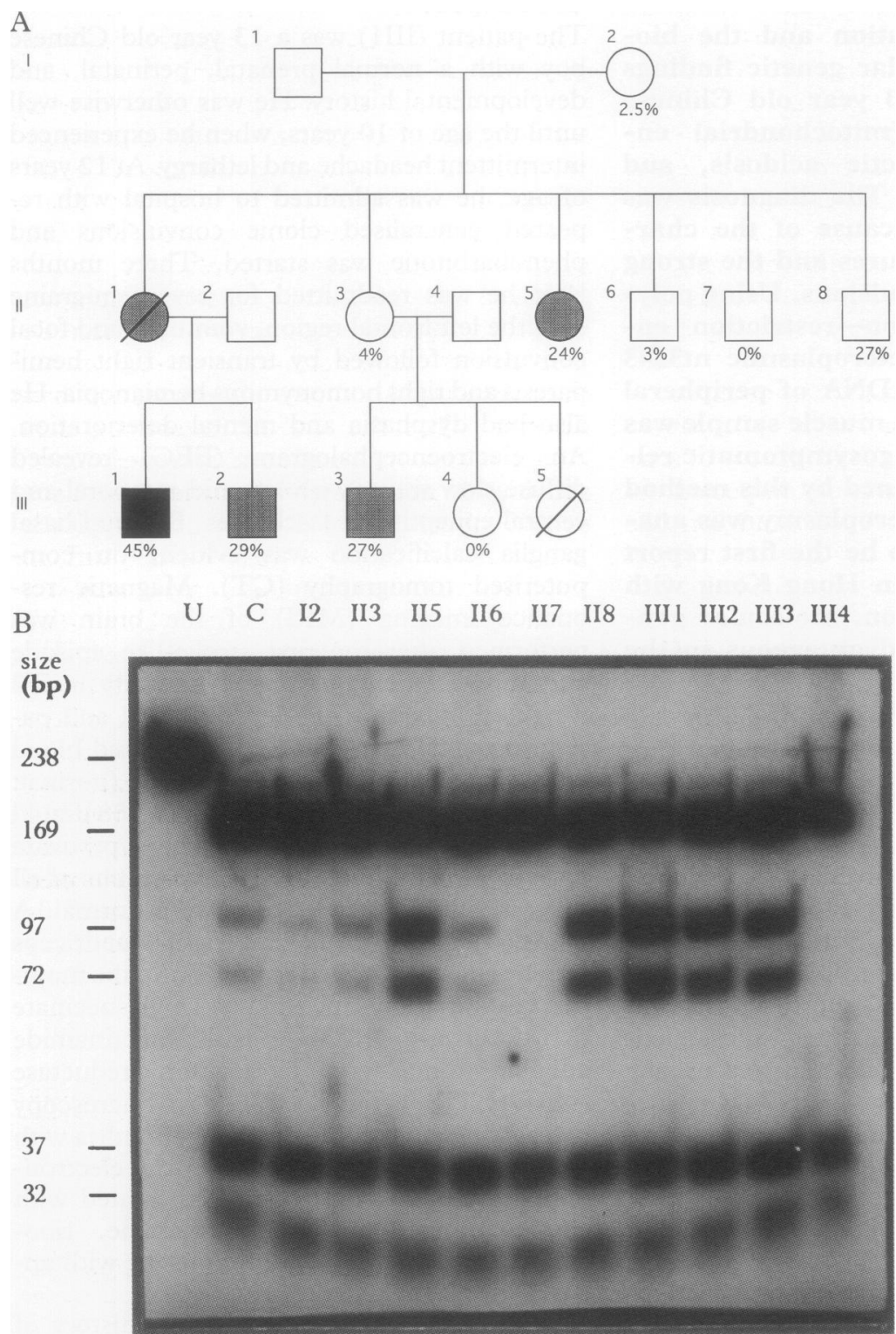

(A) Pedigree of the family with MELAS. Solid symbols denote the patient with $M E L A S$; shaded symbols denote oligosymptomatic relatives. The numbers below the symbols represent the amount of mutant mtDNA in blood. (B) Restriction enzyme analysis of the PCR product from leucocytes of the MELAS patient and his family members. Digestion of normal mtDNA with HaeIII gives fragment lengths of 169,37 , and $32 \mathrm{bp}$; the presence of the nt 3243 mutation creates an additional HaeIII site that causes the $169 \mathrm{bp}$ fragment to be cut into 97 and $72 \mathrm{bp}$ fragments. $U=$ uncut $P C R$ product; $C=M E L A S$ positive control with $6 \%$ heteroplasmy. repeated generalised tonic-clonic convulsions. EEG showed diffuse slowing and there was bilateral basal ganglia calcification on CT scan. He was then treated with phenytoin, thiamine, and coenzyme $Q_{10}$. No recurrence of seizures has occurred since the first admission.

\section{Methods}

SAMPLE PREPARATION

Genomic DNA was extracted from peripheral blood samples using a salting out procedure. ${ }^{4}$ Muscle DNA was prepared from three $10 \mu \mathrm{m}$ thick formalin fixed paraffin embedded sections of the muscle biopsy tissue which measured $4 \mathrm{~mm}$ in diameter. The hydrated sections were digested with $20 \mu \mathrm{g}$ of proteinase $\mathrm{K}$ in $100 \mu \mathrm{l}$ of $50 \mathrm{mmol} / 1$ Tris buffer, $\mathrm{pH} 8.5$, containing $1 \mathrm{mmol} / 1 \mathrm{EDTA}$ and $0.5 \%$ Tween 20 , for $16 \mathrm{~h}$ at $37^{\circ} \mathrm{C}$. The digestion mixture was heated to $95^{\circ} \mathrm{C}$ for $10 \mathrm{~min}$ to inactivate proteinase $\mathrm{K}$. Ten microlitres of the heated digest was used directly for polymerase chain reaction (PCR).

\section{POLYMERASE CHAIN REACTION}

The primers were homologous to the nt 3116 3134 (forward) and nt3353-3333 (backward) parts of the mtDNA sequence. Between 50 and $100 \mathrm{ng}$ of total DNA was amplified in a $25 \mu \mathrm{l}$ reaction mixture containing $1 \times \mathrm{Mg}$-free Promega Taq DNA polymerase buffer, $200 \mu \mathrm{mol} / 1$ each dTNP, $1.5 \mathrm{mmol} / 1 \mathrm{MgCl}_{2}, 0.5 \mu \mathrm{mol} / 1$ each primer, and one unit of Taq DNA polymerase (Promega). Using an Ericomp temperature cycler the reactions were heated to $94^{\circ} \mathrm{C}$ for 2 min followed by 25 cycles of $60 \mathrm{~s}$ denaturation at $94^{\circ} \mathrm{C}, 90 \mathrm{~s}$ annealing at $55^{\circ} \mathrm{C}$, and $3 \mathrm{~min}$ extension at $72^{\circ} \mathrm{C}$. In the final cycle, the reaction was held at the $94^{\circ} \mathrm{C}$ denaturation step while $2 \mu \mathrm{Ci} \alpha{ }^{32} \mathrm{P}-\mathrm{dCTP}$ were added to each tube. The cycle was completed, followed by a final extension of $8 \mathrm{~min}$.

Quantitative analysis of the nt3243 A $\rightarrow \mathrm{G}$ mutation was performed according to the published procedures of Moraes et al. ${ }^{5}$ The PCR products were digested with 10 units of HaeIII (NEB) at $37^{\circ} \mathrm{C}$ for $2 \mathrm{~h}$. They were loaded on to a $16 \mathrm{~cm} 12 \%$ acrylamide:bis (29:1) gel and electrophoresed in Tris-borate-EDTA buffer for $1 \mathrm{~h}$ at $15 \mathrm{~W}$. The radioactivity in each fragment was measured by placing the gel in a Betascope 603 blot analyser (Betagen).

Using the primers cited above, the PCR product size was $238 \mathrm{bp}$. Digestion of normal mtDNA with HaeIII generates fragments of 169,37 , and $32 \mathrm{bp}$; the presence of the $n t 3243$ mutation creates an additional HaeIII site that causes the $169 \mathrm{bp}$ fragment to be cut into 97 and 72 bp fragments.

\section{Results}

The point mutation at nt 3243 of mtDNA was found in the index patient (III1) and in other family members (I2, II3, II5, II6, II8, III1, III2, and III3). The gene defect was not found in the peripheral blood leucocytes of II7 and III4. The degree of heteroplasmy containing the mutant mtDNA in blood was determined 
and the results are shown in the figure. The amount of mutant mtDNA in the patients' blood showed an approximate correlation with the presence of symptoms. Individuals I2, II3, II6, II7, and III4 with low or no mutant mtDNA $(0-4 \%)$ in the blood are apparently asymptomatic.

The patient's brother (III2), who has the second largest amount of mutant DNA in the leucocytes (29\%), developed his first episode of repeated tonic-clonic convulsion at the age of 16,3 months after this test was performed. Our index patient (III), who is severely affected, has $90 \%$ mutant DNA in his muscle tissue.

\section{Discussion}

Mitochondrial encephalomyopathy, lactic acidosis, and stroke-like episodes (MELAS) syndrome is a maternally inherited disease. In 1990, Goto $e t a l^{2}$ found an nt3243 A $\rightarrow$ G mutation in the tRNA ${ }^{\text {Leu(UUR) }}$ gene of mtDNA in a MELAS patient when they screened the whole mitochondrial genome by means of DNA sequencing. This mutation was subsequently found in $80 \%$ of MELAS patients. ${ }^{3}$ The disease has mainly been reported in Caucasian populations, and there have been few cases in the Chinese. ${ }^{67}$ We now report the first case of MELAS syndrome with documented nt3243 $A \rightarrow G$ mutation in mtDNA of a Hong Kong Chinese family.

In this family, although the index case's mother (II1) had a long history of repeated convulsions and a strong family history of seizures, MELAS syndrome was not suspected. As the presence of $n+3243 \mathrm{~A} \rightarrow \mathrm{G}$ mutation has been demonstrated in her sons and her siblings, it is highly likely that the mother (II1) also had the mutation. This was later supported by the test result on the maternal grandmother (I2), who showed a mutant heteroplasmy of $2 \cdot 5 \%$. This is not unusual for MELAS as it can present in childhood, adolescence, or adulthood. Our report clearly indicates that the diagnosis of MELAS syndrome can easily be made once it is suspected. Blood lactate and pyruvate concentrations are raised in MELAS patients, particularly during acute episodes, and the molar ratio of lactate to pyruvate is typically $>20{ }^{8}$ However, the finding of normal values with this test does not rule out the diagnosis. Other non-invasive investigations, such as CT and MRI examination of the brain, can further suggest the diagnosis ${ }^{9}$ and a tentative diagnosis can be made after the demonstration of ragged red fibres in skeletal muscle. Eventually, the diagnosis should be confirmed by DNA mutation analysis.

Although the amount of mutant mtDNA can vary widely among different tissues, our results from mutation analysis of the peripheral blood samples of the MELAS family members show a good correlation with the presence of symptoms (figure). As shown in the figure, the degree of heteroplasmy varies greatly between siblings and between generations. This phenomenon is frequently observed in pedigrees that are segregating a mitochondrial DNA mutation.
The patient's brother (III2) had the second largest amount of mutant mtDNA and ragged red fibres in the muscle biopsy; however, he had had no history of convulsions over his first 16 years. The other relatives with few symptoms, II5 and III3, have lower mutant mtDNA content $(24 \%$ and $27 \%)$ in the blood, and showed symptoms of status epilepticus and encephalopathy since the ages of 20 and 8 years respectively. These results indicate that the degree of heteroplasmy in blood does not always correlate with the degree of heteroplasmy in brain tissues. However, it does provide a rough guideline to the amount of mutant mtDNA that may be present in other tissues. This proved to be the case, since 3 months after the DNA analysis was performed, patient III2 developed his first episode of generalised tonic-clonic convulsion.

The diagnostic approach to mitochondrial disorders has recently been reviewed. ${ }^{3}$ For most patients suspected of defective oxidative phosphorylation, the evaluation of a muscle biopsy by means of enzyme histochemistry and electron microscopy can be useful in supporting the diagnosis. However, the absence of ragged red fibres does not exclude mitochondrial disorders and, because it is invasive, this test is not suitable for family screening. The final diagnosis would best be confirmed by biochemical or molecular genetic techniques. However, MELAS includes one or more deficiencies of respiratory chain complexes and these defects also occur in other mitochondrial diseases. Thus the lack of respiratory chain complexes is non-specific and assays of enzyme activities do not differentiate patients with suspected mitochondrial diseases phenotypically. In addition, such assays are technically difficult and labour intensive and are only available in a few laboratories. ${ }^{8}$ On the other hand, diagnosis by PCR-restriction enzyme analysis is relatively simple, rapid, easily adaptable to preexisting molecular genetics laboratory facilities, and can be performed on leucocytes in peripheral blood. ${ }^{10}$ Furthermore, the characteristic heteroplasmic heredity of mitochondrial diseases can be demonstrated clearly and the degree of heteroplasmy can easily be quantified. Thus this method is extremely valuable in the confirmation of the diagnosis of mtDNA disorders, screening of affected family members, and genetic counselling.

We would like to thank Dr Julian Williams at the Children's Hospital of Los Angeles for helpful discussion, Dr L K Lau, Department of Pathology, Princess Margaret Hospital, Hong Kong, for histological examination of the muscle biopsies, and $\mathrm{Mr} \mathrm{H} \mathrm{T} \mathrm{Au} \mathrm{for} \mathrm{preparation} \mathrm{of} \mathrm{the} \mathrm{photomicrograph.}$

1 Pavlakis SG, Phillips PC, DiMauro S, DeViro DC, Rowland LP. Mitochondrial myopathy, encephalopathy, lactic acidosis and strokelike episodes: a distinctive clinical syndrome. Ann Neurol 1984;16:481-8.

2 Goto Y, Nonaka I, Horai S. A mutation in the tRNA ${ }^{\text {Leu(UUR }}$ gene associated with the MELAS subgroup of mitochondrial encephalomyopathies. Nature 1990;384:651-3.

3 Shoffner JM, Wallace DC. Oxidative phosphorylation diseases and mitochondrial DNA mutations: diagnosis and treatment. Annu Rev Nutr 1994;14:535-68.

4 Lahiri DK, Nurnberger JL. A rapid non-enzymatic method for the preparation of HMW DNA from blood for RFLP studies. Nucleic Acids Res 1991;19:5444.

5 Moraes CT, Ricci E, Bonilla E, DiMauro S, Schon EA

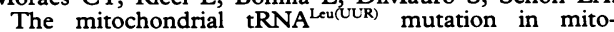


chondrial encephalomyopathy, lactic acidosis, and strokelike episodes (MELAS): genetic, biochemical, and morphological correlations in skeletal muscle. Am f Hum Genet 1992;50:934-49.

6 Lee ML, Chaou WT, Yang AD, Jong YJ, Tsai JL, Pang CY, et al. Mitochondrial myopathy, encephalomyopathy, lactic acidosis and strokelike episodes (MELAS): report of a sporadic case and review of the literature. Acta Paediat Sin 1994;35:148-56.

7 Huang CC, Chen RS, Chen CM, Wang HS, Lee CC Pang CY, et al. MELAS syndrome with mitochondrial
tRNA ${ }^{\text {Leu(UUR) }}$ gene mutation in a Chinese family. $\mathcal{f}$ Neurl Neurosurg Psychiatry 1994;57:586-9.

Stern HJ. Lactic acidosis in paediatrics: clinical and laboratory evaluation. Ann Clin Biochem 1994;31:410-9.

9 Barkovich AJ, Good WV, Koch TK, Berg BO. Mitochondrial disorders: analysis of their clinical and imaging characteristics. Am $\mathcal{F}$ Neuroradiol 1993;14:1119-37.

10 Hammans SR, Sweeney MG, Brockington M, MorganHughes JA, Harding AE. Mitochondrial encephalopathies: molecular genetic dianosis from blood samples. 1991;337:1311-3.

\title{
Identification of a thrombin receptor with factor $\mathrm{Xa}$ receptor and tissue factor in human pancreatic carcinoma cells
}

\author{
A K Kakkar, N R Lemoine, S R Stone, D Altieri, R C N Williamson
}

Department of Surgery, Royal Postgraduate Medical School, London, UK A K Kakkar

R C N Williamson

\section{Imperial Cancer} Research Fund, London, UK

N R Lemoine

Department of

Haematology,

University of

Cambridge, UK

$S$ R Stone

Department of Pathology,

Yale University,

New Haven

Connecticut, USA

D Altieri

Correspondence to Professor R C N Williamson,

Department of Surgery,

Royal Postgraduate Medical School, Du Cane Road, London W12 0NN.

Accepted for publication 22 June 1995

\begin{abstract}
Venous thromboembolism is a common feature of pancreatic cancer. The underlying mechanism is unclear, but is likely to involve thrombin generation on the cell surface. Human pancreatic carcinoma cell lines $(n=8)$ have been studied immmunohistochemically for the expression of tissue factor, factor $\mathrm{Xa}$ receptor, and thrombin receptor. Each antigen had a distinct pattern of immunoreactivity in cell membrane and cytoplasm. Tissue factor was predominantly localised to the membrane, whereas thrombin and factor $X a$ receptor were largely cytoplasmic in distribution. The results support the hypothesis of a coagulation cascade that starts with tissue factor, leads to thrombin generation, and might confer a biological advantage on tumour cells.

(f Clin Pathol: Mol Pathol 1995;48:M288-M290)
\end{abstract}

Keywords: Thrombin receptor, pancreatic cancer.

Thrombosis is a common complication of malignant disease and pulmonary embolism is the second commonest cause of death in cancer patients. ${ }^{1}$ Adenocarcinoma of the pancreas is associated with a particularly high incidence of thromboembolism. We have previously reported that the expression of the cell surface procoagulant tissue factor (TF), the physiological initiator of blood coagulation, correlates with histological grade in this disease; normal pancreatic tissue shows no immunoreactivity whereas poorly differentiated tumours have strong immunoreactivity in nearly $80 \%$ of cases. $^{2}$ This work supported our observations that the procoagulant activity in human pancreatic carcinoma cell lines is very high, varying from 14 to 6600 thromboplastin units, with at least $86 \%$ of this activity being TF dependent in each case. ${ }^{3}$ These cells also possess a high prothrombinase activity, a prerequisite to efficient cell surface thrombin generation.

Thrombin is generated by tumour cells in large quantities, therefore explaining the histological observation of peritumoral fibrin deposition ${ }^{4}$ and providing a possible mechanism for the hypercoagulable state seen in cancer patients. However, thrombin possesses a number of important functions other than its role in haemostasis, including effects on endothelial cells such as promotion of arachidonic acid metabolism and release of tissue factor, von Willebrand factor, tissue plasminogen activator, and plasminogen activator inhibitor. ${ }^{5}$ In tumour cells it has been shown to promote synthesis and release of urokinase plasminogen activator. ${ }^{6}$ It is also an important mitogen to normal cells such as fibroblasts and smooth muscle cells that play a key role in atherogenesis. ${ }^{7}$ Thrombin is also mitogenic to tumour cells, potentiating the proliferative response to insulin, epidermal growth factor, and transferrin. ${ }^{8}$

Other activated serine proteases generated as a result of the activation of coagulation have roles outside normal haemostasis and are mitogenic. Of particular interest is factor $\mathrm{Xa}$, the factor occupying the pivotal position in the normal coagulation pathway. Recently a specific receptor (effector cell protease receptor-1 (EPR-1)) for this serine protease has been identified and cloned and shown to be of functional significance. ${ }^{9}$ In this study we have 